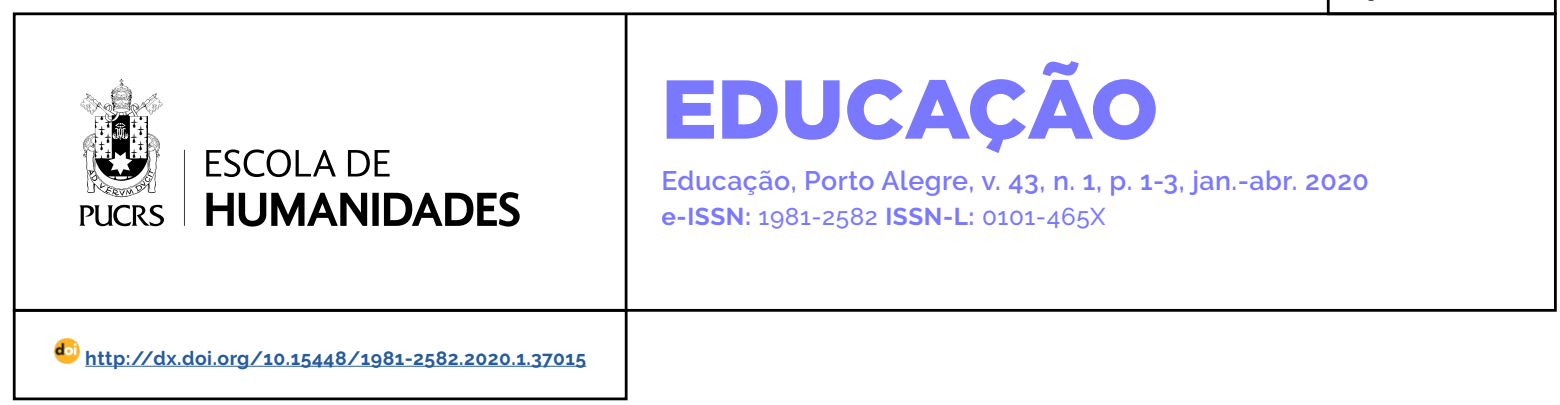

APRESENTAÇÃO

\title{
Intervenção Precoce na Infância centrada na familia: práticas e pesquisa
}

\section{Family Centred Early Childhood Intervention: practices and research}

\section{Marlene Rozek ${ }^{1}$ \\ orcid.org/0000-0001-8740-6166 marlene.rozek@pucrs.br}

\section{Ana Maria Serrano ${ }^{2}$ \\ orcid.org/0000-0002-6117-4050 serrano@ie.uminho.pt}

Recebido em: 7 fev. 2020. Aprovado em: 14 fev. 2020 Publicado em: 25 mai. 2020.

\section{(c) (i)}

Artigo está licenciado sob forma de uma licença Creative Commons Atribuição 4.0 Internacional.
A presente coletânea sobre Intervenção Precoce na Infância (IPI) congrega um conjunto de textos sobre a temática de autoria de pesquisadores da área, de diversos países da Europa, dos EUA e do Brasil e vem contribuir para esse campo de investigação. A preocupação com a infância é um tema que se encontra na pauta de vários organismos internacionais (Organização das Nações Unidas; Organização das Nações Unidas para a Educação, a Ciência e a Cultura; Organização Mundial da Saúde; Fundo das Nações Unidas para a Infância; The European Association on Early Childhood Intervention; International Society of Early Intervention) assim como em documentos como a Declaração Universal dos Direitos Humanos (1948), a Convenção sobre os Direitos da Criança (1989), a Declaração de Salamanca (1994), a Convenção sobre os Direitos das Pessoas com Deficiência (2006), entre outros. A ciência do neurodesenvolvimento tem mostrado que as experiências precoces apresentam um papel significativo no desenvolvimento humano, assim como as características dos ambientes familiar e social em que a criança vive e se desenvolve. As práticas de IPI centradas na familia estão fundamentadas conceitual e empiricamente em modelos de desenvolvimento que sugerem a importância da experiência inicial e a maior maleabilidade do desenvolvimento precoce, pois os primeiros anos constituem uma "janela de oportunidades" para a mudança no desenvolvimento e para reparar trajetórias da arquitetura cerebral que podem ser ruptura pelas predisposições genéticas e pelos problemas no desenvolvimento. Colocar o conhecimento científico sobre a Intervenção Precoce na Infância a serviço das políticas públicas, das famílias e dos profissionais envolvidos, visando proporcionar o bem-estar e a qualidade de vida às crianças e suas familias, é o que mobiliza este grupo de experientes e renomados pesquisadores do Brasil, Portugal, Espanha, EUA e Irlanda.

Considerando tais questões, este dossiê analisa e reflete a perspectiva ecológica da Intervenção Precoce na Infância (IPI) e as práticas centradas nas familias em diferentes contextos socioculturais, com ênfase nos apoios e nas interações sociais; a interdisciplinaridade e a intersetorialidade como formas de estruturar e de organizar os serviços; e a importância 
das práticas centradas na familia com base em evidências científicas e na competência emocional de todos os envolvidos no processo de intervenção, nas práticas colaborativas entre pais e profissionais. Por fim, busca a discussão sobre as condições de saúde da criança e da familia bem como a fragilidade das políticas públicas para crianças de zero a três anos em contextos específicos. A seguir, apresentamos, de forma geral, os textos que compõem essa coletânea.

O artigo "Bebês com deficiência no Brasil: um olhar a partir dos programas governamentais e pesquisas nacionais", de Marlene Rozek e Gabriela Dal Forno Martins apresenta os resultados do mapeamento de programas governamentais e a produção científica brasileira sobre as políticas públicas de inclusão nos três primeiros anos de vida. As autoras ressaltam a urgência da proposição e da avaliação de políticas públicas intersetoriais para essa população, que visem a inclusão de forma mais abrangente, proporcionando bases favoráveis para o desenvolvimento do bebê e da criança pequena.

No artigo "'I felt alone': the Importance of Social Support for Early Intervention", Marilyn EspeSherwindt e Ana Maria Serrano demonstram que o apoio social, o bem-estar pessoal, os estilos de interação dos pais e o desenvolvimento infantil estão conceitual e empiricamente relacionados, e que as mudanças no desenvolvimento infantil se atribuem muito mais ao apoio social e ao bem-estar da família, do que ao seu status socioeconômico. As pesquisadoras concluem que os apoios sociais desempenham, de fato, um papel essencial no planejamento da intervenção com crianças pequenas e suas famílias.

O estudo de Noelia Orcajada Sánchez e Francisco Alberto Garcia Sánchez "Filtros mentales, coaching y Atención Temprana centrada en la familia", busca compreender a interpretação que o adulto faz sobre sua realidade e suas competências, permitindo desta forma, que o profissional se coloque no lugar da família, de modo a conseguir seu envolvimento a partir de sua própria perspectiva e linguagem. Nesse artigo, são abordados a identificação e o entendimento dos filtros do adulto.
"La Competencia Emocional en Atención Temprana: Perspectivas de los padres y de los profesionales", de autoria de Claudia Tatiana Escorcia-Mora e Pedro Enrique Díaz Martínez procura identificar a importância que os pais e profissionais atribuem às competências emocionais e suas implicações no desenvolvimento da criança. Os resultados sugerem que os profissionais e os pais acreditam que gerem os aspectos emocionais, no entanto, a sua gestão é apenas em algumas categorias e de forma empírica, com base na sua experiência pessoal.

Robin A. McWilliam e Pau García Grau, no artigo "Towards Implementation of an Early Intervention Model by a Paraguayan Organization", descrevem o processo de transformação de um centro de reabilitação no Paraguai para um programa de intervenção precoce de última geração. As implicações para a fidelidade do modelo baseado em rotinas são destacadas, observando o contexto específico da cultura paraguaia.

No artigo "Can you hear me? - Accessing the voice of the child with Autism and their parent", Miriam Twomey aborda estruturas conceituais filosóficas que exploram conceitos de movimento e de engajamento como forma de dar voz a crianças com e sem diagnóstico de TEA (Transtorno do Espectro Autista) e seus pais, através de estudos de caso qualitativos e longitudinais, em intervenções baseadas nas Artes Criativas. Dessa forma, o valor potencial do uso das Artes Criativas como meio de envolver as crianças com TEA é discutido.

Por fim, o estudo de Ana Paula da Silva Pereira, Andrea Perosa Saigh Jurdi e Ana Isabel Martins de Sá, "Intervenção Precoce e Transtorno do Espectro do Autismo: Avaliação da Interação Social", analisou a convergência entre pais e profissionais relativamente à avaliação da área da interação social em 128 crianças com TEA, entre 3 e 6 anos, apoiadas pelo sistema de intervenção precoce em Portugal. Os resultados concluem que os pais avaliam mais positivamente a dimensão da interação social comparativamente com os profissionais. Outras variáveis também são discutidas no estudo. 
Acreditamos que as discussões selecionadas para este dossiê fomentem outros estudos e inspirem políticas e práticas de Intervenção Precoce na Infância, considerando os bebês, suas familias e seus contextos.

Desejamos boa leitura!

\section{Endereço para correspondência}

Marlene Rozek

Pontificia Universidade Católica do Rio Grande do Sul

Av. Ipiranga, 6.681, Prédio 8, sala 304

Partenon, 97010-082

Porto Alegre, RS, Brasil 